\title{
LOS PRESUPUESTOS FUNCIONALES O POR PROGRAMAS Y SU APLICACION EN EL PERU
}

La técnica de elaboración de presupuestos por programas está basada en la premisa siguiente: el presupuesto debe mostrar a nivel de cada servicio, lo que el gobierno hace, realiza y no solamente los bienes y servicios que el gobierno adquiere, que no son sino medios para lograr objetivos que el presupuesto debe mostrar: kilómetros de carretera para construirse, hectáreas por irrigarse; número de maestros por formarse, etc. De esta manera el presupuesto por programas es una herramienta muy valiosa para prever las realizaciones concretas de un gobierno, y para luego, una vez ejecutado el presupuesto, evaluar los resultados obtenidos.

La finalidad de este trabajo es explicar en forma somera los conceptos generales cuyo conocimiento es indispensable para comprender la técnica presupuestaria funcional o por programas. Este trabajo incluye también algunos comentarios sobre la actual aplicación de esta técnica en el Perú. Por su corta extensión este artículo no comprende muchos puntos que son de importancia, pues sólo pretende ser una introducción al tema. Veamos en una primera parte las nociones fundamentales sobre las cuales descansa este sistema presupuestario, y en una segunda parte, su actual aplicación en el Perú.

La unidad básica del piesupuesto funcional es el programa. El Manual de Presupuestos de las Naciones Unidas define el programa de la siguiente manera: "se entiende por programa una de las finalidades principales para las cuales se establece una entidad del gobierno; incluye todas las funciones $y$ actividades dedicadas a conseguir ese objetivo." Gonzalo MARTNER en su "Curso de programación presupuestaria" define el programa como "un instrumento destinado a cumplir las funciones del Estado, por el cual se establecen objetivos - metas cuantificables a cumplirse mediante el desarrollo de un conjunto de acciones integradas $y / 0$ de otras específicas coordinadas con los recursos humanos, materiales y financieros asignados, con un costo global y unitario determinado y cuya ejecución queda a cargo de una unidad administrativa del gobierno. Por ejemplo, dentro de la función educación se pueden abrir los programas de educación primaria, educación media, educación superior, etc." También se describe al programa como un "conjunto de actividades o proyectos coordinados, capaces de producir resultados homogéneos y cuantificables."

1

El carácter valorable de los resultados del programa (carácter que proviene del hecho de que dichos resultados son homogéneos y cuantificables) es de la mayor importancia porque permite evaluar en general los objetivos perseguidos por la política gubernamental y por ello, se convierte el programa en la unidad presupuestaria básica: el programa es el centro y objeto de la asignación de recursos que implica una unidad ejecutora de las metas asignadas, una unidad de gestión, una unidad contable y una unidad responsable de sus resultados materiales y financieros anuales.

La característica esencial de un programa es que da lugar a la aparición de un producto final que de una $u$ otra manera puede valorarse, lo cual proporciona una base para las decisiones que deben tomar los poderes públicos en materia de distribución de los recursos fiscales. En otras palabras, un programa debe ser, en lo posible, evaluable y esto significa que debe contener una meta o resultado final que sea homogéneo, cuantificable y significativo. Si falta alguna de estas caracteristicas el programa no será evaluable; en cambio, si se dan simultáneamente, el programa sí lo es, convirtiéndose asi en un instrumento de programación a corto plazo. 
La homogeneidad es una caracteristica fundamental del programa, porque la unidad del mismo viene dada por la unidad conceptual del resultado; si éste fuera heterogéneo no habria posibilidad de comparar metas y obtener costos unitarios. Así, por ejemplo, la producción de cereales, la irrigación de tierras, la recaudación de impuestos directos constituyen tres pogramas, cada uno de los cuales muestra resultados finales homogéneos, a saber, toneladas de cereales producidos, hectáreas irrigadas, impuestos recaudados. La homogeneidad del programa radica en que cada tonelada de cereal es igual a otra, que cada hectárea irrigada es igual a otra, etc. Desgraciadamente no siempre es posible presentar metas homogéneas. Para que el programa sea evaluable es preciso que la meta sea también cuantificable, es decir que se pueda medir en unidades físicas. Serán cuantificables, por ejemplo, alumnos educados, kilómetros de carreteras construidas, hectáreas irrigadas. Pero hay programas cuyos resultados por naturaleza no son cuantificables. Tal seria el caso de un programa de administración de justicia. Pero será útil una estadística sobre el número de juicios tramitados, juicios sentenciados, etc., aunque no constituye una cuantificación del resultado final, pues éste es intangible $e$ inconmensurable.

Por último, se requiere que la cuantificacićn del resultado del programa sea intrínsecamente significativa, es decir, que la cifra dada explique, defina y justifique por sí sola el programa (1). Cuando esto sucede, el programa se convierte en un instrumento de programación o planificación, pudiendo constituir la meta que le corresponde, la parte anual de la meta a mediano o largo plazo del plan general, en el caso de que éste exista.

Las metas que contiene cada programa deben compararse en el mismo programa, a las metas a mediano y largo plazo y al déficit nacional, si es que ello es posible.

Todo programa tiene también como elemento esencial e imprescindible: una unidad ejecutora, que será un servicio administrativo directamente responsable de todos los aspectos de la ejecución del programa, sin perjuicio de que existan también responsabilidades colaterales o subsidiarias.

La responsabilidad de la unidad ejecutora abarca todos los aspectos del programa presupuestario: la obtencićn de las metas previstas, la dirección de las actividades del programa, el manejo y la gestión de los recursos financieros, la administración del personal, etc. Esto resulta ser importante si queda bien establecido en la ley

1 Véase, JIMENEZ, Juan Ignacio, op. cit. y en la práctica, pues ello permitirá que sea más factible el deslindar responsabilidades en caso de fracaso de un programa o actividad, de incumplimiento de las metas presupuestadas, etc. Normalmente todo programa debe contener además los siguientes presupuestos: de resultados (las metas), financiero, de actividades y proyectos, de personal, de materiales y de fuentes de financiamiento.

En resumen, el programa es la unidad presupuestaria básica: el programa es el centro y objeto de la asignación de recursos que tiene una unidad ejecutora, e implica una unidad de gestión, de ejecución, de contabilidad y de responsabilidad.

La responsabilidad en la ejecución del programa significa en teoría que su gestor está sometido a un doble control: el antiguo control contable o financiero y el control por los resultados materiales obtenidos.

En el presupuesto los programas están agrupados en funciones. El presupuesto de Bolivia define a la función como: "la esfera específica de acción del Estado, como la Educación, la Salud Pública, la Defensa Nacional, etc.".

Las funciones se dividen muchas veces en subfunciones que corresponden generalmente al nivel de Dirección de Ministerio. Los programas complejos se dividen a veces en subprogramas.

\section{II}

\section{Aprobación del presupuesto funcional por el Poder Legislativo.}

La aprobación de un presupuesto funcional por el Parlamento presenta problemas que no existían en el caso de la aprobación legislativa de los presupuestos tradicionales. Podemos resumirlos en dos interrogantes: ¿puede el Poder Legislativo introducir modificaciones en la combinación de recursos de un determinado programa? ¿Puede el Poder Legislativo modificar las metas de un programa?

Con respecto a la primera cuestión debe reiterarse que un programa, cuando ha sido elaborado con seriedad, conjuga una serie de recursos que, asi combinados, permiten desarrollar actividades en orden a lograr un resultado o meta. Por ejemplo: sucede que para alcanzar determinadas metas de un programa de recuperación de tierras agrícolas se requiere contratar a diez ingenieros agrónomos. Si solamente se contrata a ocho, no se cumplirán las metas, y si de lo contrario se contrata a doce, los agrónomos excedentes, o no realizarán un trabajo efectivo o entorpecerán las labores de los demás. 
Lo mismo puede decirse si para el mismo programa se requiere adquirir cuatro tractores. Adquirir solamente dos, - comprar ocho, sería en cada caso absurdo, y esto es así, entendiéndose que cada programa contendrá en la medida de lo posible una justificación o explicación del tipo y cantidad de recursos que necesita utilizar. Si bien puede ser discutible si en el caso del programa mencionado se necesita contratar a ocho agrónomos o a diez, difícilmente el Parlamento podrá evaluar técnicamente la cantidad de agrónomos requeridos para el programa de recuperación de un número determinado de hectáreas. Es imposible tener un auténtico presupuesto por programas si el Parlamento va a tener la atribución de señalar el número de plazas de personal o la cantidad de material por consumirse en cada programa.

En cuanto a la segunda interrogante propuesta anteriormente, debe señalarse que de acuerdo con la naturaleza del Presupuesto Funcional, la atención legislativa debe centrarse en el "presupuesto de resultados" o metas de cada programa. El Parlamento debe pronunciarse sobre la calidad y la magnitud de las metas sometidas a su consideración y que justifican el programa. Así, al pronunciarse sobre las metas, el Legislativo se está pronunciando sobre el valor del programa mismo. Es por ello que el programa constituye una unidad de apropiación de fondos y una unidad de votación.

\section{III}

\section{Los presupuestos funcionales en el Perú.}

El sistema presupuestario funcional fue introducido en el Perú mediante el decreto-ley No 14260 de 21 de diciembre de 1962, que vino a constituir la primera ley orgánica sobre presupuestos funcionales. Su contenido se inspiró en las recomendaciones formuladas al gobierno peruano por técnicos en presupuestos de la CEPAL $y$ en experiencias realizadas por funcionarios peruanos en algunas reparticiones de los Ministerios de Hacienda, de Fomento y de la Defensa Nacional. La Ley Orgánica del Presupuesto Funcional actualmente vigente fue promulgada el 16 de enero de 1964. Esta ley tiene muchos aciertos y también algunos defectos graves. No es nuestro propósito analizarla en detalle en este trabajo, pues nuestro deseo es hacer algunas críticas de conjunto al actual funcionamiento del sistema presupuestal peruano y no solamente restringirnos al contenido de la ley. Estas apreciaciones sobre el sistema actual son de tipo general, sin entrar en detalles que de ser mencionados en este trabajo nos harían perder la visión de conjunto que debe caracterizarlo. $Y$ las personas, que por experiencia diaria en la función pública conocen bien esta materia, estarán de acuerdo en que estos juicios sobre el funcionamiento del actual sistema presupuestario son incompletos.

1. Es de todos conocido que en el Perú no existe un plan de desarrollo económico que merezca el nombre de tal y cuyas metas a largo y mediano plazo puedan ser tenidas en cuenta para la formulación de las metas anuales de los distintos programas del presupuesto funcional. Existen, si, prioridades fijadas por el Instituto Nacional de Planificación, pero en la práctica no son tomadas en cuenta al elaborar el proyecto de presupuesto. Es cierto que en algunos ministerios existen planes o programas sectoriales o específicos a los cuales pueden ajustarse las metas anuales de los correspondientes programas. Es cierto también, que a falta de planes o programas a mediano plazo, cada unidad de asignación puede programar sus metas de acuerdo con sus necesidades y su experiencia. $Y$ lo grave, entonces, es que en los volúmenes del Presupuesto Funcional de cualquier año no se encuentran explícitas metas de ningún tipo. No existe ni una descripción de metas por alcanzarse en cada unidad de asignación, ni una descripción de las funciones de éstas.

Un programa sin metas no tiene de programa sino el nombre. Con sólo tomar en cuenta este hecho, podemos afirmar que el sistema de presupuesto por programas ha sido desnaturalizado en nuestro país.

La única ventaja del sistema presupuestario actual, tal como es practicado, viene a ser el hecho de que constituye una racionalización o mejor presentación de un presupuesto tradicional, en cuanto señala el objeto del gasto.

2. No solamente no existen planes serios, sino, lo que es más grave aún: rara vez una unidad de asignación puede prever racionalmente en forma aproximada sus actividades para el ejercicio siguiente, porque, por to general, su presupuesto tal como es aprobado por las Cámaras resulta radicalmente distinto del proyecto inicial elaborado por la misma unidad de asignación unos meses antes. Que existan diferencias entre el presupuesto aprobado para la unidad de asignación es normal. Lo que viene a ser absurdo es que las diferencias entre uno y otro sean a menudo radicales y que, conforme se va modificando el anteproyecto original en la distintas instancias (Ministerio respectivo, Ministerio de Hacienda, Consejo de Ministros, Cámaras Legislativas...), no se notifique a la unidad de asignación la realización de cambios importantes. 
3. Esto último sucede en el mejor de los casos, pues en los últimos años ha tenido lugar algo menos recomendable todavía: una vez que las unidades de asignación de un determinado ministerio han elaborado su proyecto de presupuesto para el ejercicio siguiente dedicando a sus mejores funcionarios a esa tarea de programación de actividades, y una vez que esos proyectos de presupuesto han sido consolidados a nivel ministerial y enviados al Ministerio de Hacienda, dichas unidades de asignación reciben de este último una comunicación que ordena: "repítase el presupuesto del año anterior." Esto no solamente es una negación total de lo que es un presupuesto funcional, y de lo que es la programación, sino que, además, resulia una negación de lo que es un presupuesto en términos tradicionales y una negación también de todos los principios de buena administración. $Y$ desde el punto de vista puramente financiero, una repetición forzosa del monto de los gastos del ejercicio anterior es una aberración que, entre otras cosas, lleva irremisiblemente al déficit presupuestal debido a la falsedad de las cifras.

4. Existe otro problema que está en la base de las dificultades y distorsiones que presenta el funcionamiento del sistema de presupuestos por programas en el Perú. Es el problema de las atribuciones del Poder Legislativo en materia de presupuesto. Son atribuciones muy amplias que no están sujetas a reglamentación ni a limitaciones. La Constitución y las leyes pertinentes señalan que compete al Parlamento aprobar el presupuesto cada año. Sin embargo no existe ninguna disposición constitucional o legal que señale al Parlamento un plazo para la aprobación del presupuesto, pasado el cual el proyecto de presupuesto presentado por el Ejecutivo en su término, quedaria automáticamente aprobado. Tampoco existe ninguna disposición que prohiba o limite la iniciativa del Parlamento en la creación de nuevos gastos o de nuevas cargas tributarias (salvo aquella disposición que obliga a crear la financiación correspondiente cuando el Parlamento aprueba un gasto por iniciativa propia, regla ésta que no se cumple).

Tampoco ha sido posible incluir en la Ley Orgánica de Presupuesto algún articulo limi:ando la airibución parlamentaria de modificar indiscriminadamente los insumos necesarios para lograr las metas propias de cada programa (presupuesto de personal, de material, etc.), en el supuesto de que existieran metas.

En todo caso el Parlamento no debería tener la atribución de aumentar los gastos ni de aumentar las plazas de personal, ni de crear nuevas unidades de asignación cuando ello no sea propuesto inicialmente por el Poder Ejecutivo. En caso contrario toda planificación o toda programación se vuelve imposible e ilusoria.

5. Sin embargo, en la situación actual, en la cual el Poder Ejecutivo no parece haber mostrado un deseo de programar seriamente sus actividades ni de racionalizar la administración pública, ni tampoco ha presentado a las Cámaras proyectos de presupuesto correctamente elaborados, esta amplitud de las atribuciones del Poder Legislativo ha resultado en algunos casos beneficiosa. Suele suceder a veces que jefes de unidades ejecutoras logran conseguir de la comisión de presupuesto de una de las Cámaras la inclusión en el proyecto de presupuesto de algunas partidas cuya existencia es indispensable para el funcionamiento de dichas unidades y que habian sido eliminadas por el Ministerio de Hacienda.

$Y$ parece interesante anotar que a raíz de la devaluación monetaria de setiembre de 1967 y de la seria crisis fiscal que la acompaña, el Congreso ha adoptado el papel de moderador del gasto público tratando real o aparentemente de eliminar el déficit presupuestal y de frenar los gastos del sector público.

A pesar de que los criterios con que se calculan los ingresos, se disminuyen ciertos gastos y se cuadran cifras que son muy discutibles, sería interesante poner en relieve y estudiar el proceso de aprobación del presupuesto de 1968 por el Parlamento y compararlo con el proceso de aprobación de los presupuestos de los años anteriores. $Y$ en el futuro será interesante estudiar también el "modus operandi" de la aprobación de los próximos presupuestos. Es posible que en este sentido la discusión y aprobación del presupuesto de 1968 marquen un hito importante en la vida parlamentaria peruana de estos últimos años (2).

\section{IV}

En conclusión, puede decirse que el sistema presupuestario funcional, adoptado por la ley en el Perú desde 1963, se halla desnaturalizado en la práctica. No puede decirse que los presupuestos del gobierno peruano sean presupuestos por programa. $Y$ esto es así porque, finalmente el presupuesto por programa implica una cier-

2 No hemos tratado de otros problemas del procedimiento presupuestario actual, como el de la responsabilidad demasiado compartida con los jefes de unidades ejecutoras ni el problema del control preventivo por parte de la Contraloría. Tampoco hemos tratado acerca de los serios problemas legales y presupuestales que presenta el subsector público independiente. 
ta racionalización de la administración pública y de las finanzas del Estado. Implica también una voluntad en este sentido por parte de los dirigentes políticos del pais, voluntad generalmente inexistente en la actualidad.

Es posible que los técnicos que a lo largo de los años han ido elaborando este sistema presupuestario y quienes lo introdujeron en el país hayan pensado que los presupuestos por programas iban a traer ccnsigo una racionalización de la administracićn. Si pensaron eso anduvieron equivocados. Pues, como tenia que ser, sucedió lo contrario: las prácticas políticas y administrativas tradicionales obligaron al nuevo sistema a adaptarse a sus requerimientos, y para ello era necesario que aquél sufriera transformaciones que lo tornasen inoperante.

Finalmente, cabe preguntarse si el sistema de presupuestos por programas es el más adecuado para la realidad del país, y aún más: cabe preguntarse si ese sistema no peca de utópico en el sentido de que posiblemente plantee en el terreno de los hechos lo que realmente corresponde al "deber ser". ¿Es posible en la práctica proyectar y ejecutar programas con metas anuales que constituyen partes bien calculadas de metas a mediano y a largo plazo de un plan? ¿Es posible siempre calcular racionalmente los insumos necesarios para lograr dichas metas? La experiencia, con el tiempo, nos dará las respuestas.

\section{BIBLIOGRAFIA BASICA}

CASTILlO, Juan Lino.- El Derecho Presupuestario en el Perú. Editorial P. T. C. M. Lima, 1950.

JIMENEZ, Juan Ignacio.- Programación presupuestaria. Segundo curso intensivo de capacitación en materia de desarrollo económico. Publicación mimeografiada de las Naciones Unidas (CEPAL - DOAT) y del Instituto de Planificación del Perú-Lima, 1963.

MARTNER, Gonzalo.- Presupuestos gubernamentales. Editorial Universitaria, Santiago de Chile, 1962.

ONRAP, Diagnóstico preliminar de la administración pública peruana y propuestas de reforma. Diciembre de 1965.

O. N. U.- Manual de presupuestos por programas o actividades. Santiago de Chile, 1962.

VILLARAN, Manuel Vicente.- Anteproyecto de Constitución de 1931, por la Comisión que él presidiera. Lima, 1962.

LEY ORGANICA DEL PRESUPUESTO DE 1964 (LEY 14816) - Publicación del Ministerio de Hacienda y Comercio. Lima, 1964. 